\title{
Differential genes expression biomarkers for menstrual and peripheral blood stains analysis
}

\author{
Asmaa Mohammad Moawad ${ }^{1 *} \mathbb{D}$, Hala saied zaghlol', Mervat Hamdy Abdelsalam', Amani Abdelfattah', \\ Dina Sabry ${ }^{2}$ and Adel Atef ${ }^{3}$
}

\begin{abstract}
Background: Identification of menstrual blood is an important issue in forensic biology, but there are no confirmatory methods for its detection. This study aimed to investigate the use of mRNA markers (hemoglobin alpha (HBA), matrix metalloproteinases 7 \&11 (MMP7 \&MMP11) as forensic markers for differentiation between menstrual and peripheral blood stains.

Results: HBA was present in all peripheral and menstrual blood samples with higher levels in peripheral blood. MMP 7\&11 were absent in peripheral blood samples. MMP7 levels were higher than that of MMP11 throughout days of menstruation (days 1-5).

Conclusion: HBA, MMP7\&MMP11 could be useful markers for differentiation between menstrual and peripheral blood stains. Further studies should be conducted on various fabrics and other body fluids.
\end{abstract}

Keywords: Menstrual blood, mRNA, MMP7, MMP11, HBA, Peripheral blood

\section{Background}

Identification of biological materials (e.g. body fluids, blood) which are frequently recovered from crime scenes offers crucial information to investigation of the violent crimes (Takamura et al., 2017).

In the field of forensic biology, the ability to differentiate between menstrual and peripheral blood is an issue of particular importance especially in setting of alleged sexual assaults (Virkler \& Lednev, 2009). Over many years, several methods have been proposed for distinguishing the menstrual blood from peripheral one (Jakubowska et al., 2014). However, these methods have not proven to be reliable or confirmatory. Recently, mRNA profiling has taken the widest interest for use in forensic casework based on its universality, modification and easily application to detect various body fluids (Roeder \& Haas, 2013). In terms of markers, matrix metalloproteinases (MMP7, MMP10 and MMP11) involved in tissue remodeling and the cleavage of

\footnotetext{
* Correspondence: asmaamoawad90@gmail.com

${ }^{1}$ Department of Forensic Medicine and Clinical Toxicology, Faculty of

Medicine, Cairo University, Cairo, Egypt

Full list of author information is available at the end of the article
}

extracellular matrix proteins were the first mRNA markers detected for menstrual blood (Jakubowska et al., 2014). While d-aminolevulinate synthase 2 (ALAS2) and hemoglobin alpha (HBA) markers are found in both peripheral and menstrual blood (Roeder \& Haas, 2013).

Therefore, the current study aimed to investigate the use of mRNA markers (HBA, MMP7 \&MMP11) as forensic markers for differentiation between menstrual and peripheral blood stains.

\section{Methodology \\ Study design and setting}

A prospective, cross-sectional study was given to a purposeful, convenient sample of normal, healthy adult volunteers gathered between January to December 2016.

\section{Study population}

Ninety eligible participants aged 14 to 59 years were recruited during the study period. The sampled population were categorized into 2 groups, 45 for each. Group I (Study Group) included healthy females aged 14 to 49 years followed up within 1 st 5 days of their menses. The second 
group (Control Group) included proportionate distribution of healthy male and female individuals. Potential participants who had hematological disorders, coagulopathies, hepatic diseases, and females with menstrual disorders were excluded from the study.

The study represents collaborative research between Forensic Medicine and Toxicology Department and Biochemistry and Molecular Biology Unit at The Medical Biochemistry Department, Faculty of Medicine, Cairo University, Egypt. The study was conducted according to the declaration of Helsinki and the protocol was approved by Ethics Research Board of both departments (World Medical Association, 2001). All participants provided written informed consents before being enrolled in the study.

\section{Study measurements}

Ninety blood samples of approximately $5 \mathrm{ml}$ were drawn from each participant to measure MMP7, MMP11 and HBA. Samples collected from the study group $(n=45)$ were menstrual blood, while those collected from the control group ( $\mathrm{n}=45)$ were peripheral (venous) one. In this context, samples have been regarded to range in age among both groups and the day of the menstrual cycle in Group I.

\section{RNA extraction}

Nucleic acid extraction kit (NucleoSpin $\left.{ }^{\circ}\right)$ was purchased from Macherey- Nagel GmbH and Co. KG-Germany. $200 \mu \mathrm{l}$ of each studied sample was placed in collection tube with $700 \mu$ l Buffer TR lysis buffer for RNA extraction and purification according to manual instructions provided by applied kit. RNA purity was assessed by measuring concentration by Beckman dual spectrophotometer at 260-280 ultraviolet invisible wave length.

\section{Primer design and selection}

Primers were designed by Life Technologies company (Life Technologies corporation, Carlsbad, CA). For the selection of the ideal primer pair, the considered factors are included: melting temperature $\left(\mathrm{Tm}: 60-65{ }^{\circ} \mathrm{C}\right), \mathrm{GC}$ content $(40 \%-60 \%)$ and amplicon length of about 90 200 base pairs (bp).

\section{Reverse transcription and $P C R$}

The qPCR kit was provided by Bioline, a median life science company, UK (SensiFAST ${ }^{\mathrm{Tm}} \mathrm{SYBR}^{\circledR} \mathrm{Hi}$-ROX). According to manufacturer's instructions, the reactions were carried out in a total volume of $20 \mu \mathrm{L}$ containing $5 \mu \mathrm{L}$ qPCR SyGreen Mix, HRox, 2X; $1 \mu \mathrm{L}$ Forward Primer; $1 \mu \mathrm{L}$ Reverse Primer; $0.5 \mu \mathrm{L} 20$ RTase/Inhibitor Mix; $5 \mu \mathrm{L}$ Total RNA and 7.5 $\mu \mathrm{L}$ RNAse free water. The thermal cycler conditions were as follows: one cycle of reverse transcription for $10 \mathrm{~min}$ at $55{ }^{\circ} \mathrm{C}$ and initial activation for 2 min at $95{ }^{\circ} \mathrm{C}$ and 40 cycles of denaturing at $95{ }^{\circ} \mathrm{C}$ for $5 \mathrm{~s}$, annealing and extension at $60^{\circ} \mathrm{C}$ for $1 \mathrm{~min}$.

\section{Calculation of relative quantification (RQ) (relative expression)}

After the RT-PCR run, the data was expressed in Cycle threshold $(\mathrm{Ct})$. The PCR data sheet included $\mathrm{Ct}$ values of assessed genes (MMP7, MMP11 and HBA) and the reference gene (GAPDH). Therefore, target gene expression was assessed and related to reference gene as follows:

$\Delta \mathrm{Ct}$ sample $=\mathrm{Ct}$ assessed gene $-\mathrm{Ct}$ reference gene

$\Delta \Delta \mathrm{Ct}=\Delta \mathrm{Ct}$ sample $-\Delta \mathrm{Ct}$ control gene

And finally, RQ was calculated according to the following equation:

$$
\mathrm{RQ}=2^{-(\Delta \Delta \mathrm{Ct})}
$$

\section{Statistical analysis}

Data was coded and entered using the statistical package SPSS version 22. Data was summarized using mean and standard deviation. Comparison between groups was done using the nonparametric Mann-Whitney test and the One-way Analysis of Variance (ANOVA). Probability (P) values equal or less than .05 were considered as statistically significant. Correlation was done to test for linear relations between quantitative variables by Pearson correlation coefficient. The closer to 1 (+ or -) the stronger the relationship.

\section{Results}

During the study period, 90 healthy individuals, aged 1459 were eligible to participate in the current research. Characteristics of study participants are shown in Table 1. The female participants comprised $100 \%$ of the study groups and $51.1 \%(n=23)$ of the control one (Table 1$)$.

As shown in Table 2, no significant correlation was found between age of the participants and the levels of HBA in both peripheral and menstrual blood samples, MMP7 and MMP11 (Table 2).

Table 1 Baseline demographic characteristics

\begin{tabular}{lll}
\hline & Number & $\%$ \\
\hline Gender & & \\
• Males & 22 & 24.4 \\
• Females & 68 & 75.6 \\
Age in years (mean \pm SD) & $43.8 \pm 10.4$ & \\
Range & $14-59$ & \\
Residence & & 81.1 \\
- Urban & 73 & 18.9 \\
• Rural & 17 & \\
\hline
\end{tabular}


Table 2 Correlation between age of participants and HBA, MMP7 and MMP11 levels

\begin{tabular}{llllllll}
\hline & \multicolumn{2}{l}{ Peripheral } & & \multicolumn{3}{l}{ Menstrual } \\
\cline { 2 - 3 } & HBA & MMP7 & MMP11 & & HBA & MMP7 & MMP11 \\
\hline Correlation & 0.196 & & & 0.083 & 0.27 & 0.083 \\
Coefficient $(r)$ & & & & & & \\
95\% Confidence & $-0.104-$ & 0 & 0 & -2.34 & -6.49 & $-6.3-$ \\
Interval (Cl) & 0.463 & & & -4.1 & 0.24 & 0.028 \\
$P$ value & 0.197 & & & 0.58 & 0.068 & 0.85 \\
\hline
\end{tabular}

The mean levels of HBA, detected in blood samples of the entire study population, had significantly higher levels in the menstrual blood compared to the peripheral one $(P<.001)$ Fig. 1. However, those levels showed no statistically significant difference among female and male participants within the control group $(P=.866)$.

As shown in Table 3, comparison between the mean values of MMP7 and MMP11 through different days of menstruation showed no statistically significant difference. Higher mean levels were noticed among second and third days. Where the mean values of HBA showed statistically significant difference throughout 5 days of menses $(P=.01)$ (Table 4$)$, as mean level of HBA measured on day five was significantly decreased compared to mean levels of first and second days of menses $(P<.05)$.

Metalloproteinases (MPP7and11) were detected only in all menstrual blood and absent in peripheral blood samples (0\%). Comparison between different mean levels of (MMP7 and MMP11) through different days of menstruation are provided in Table 5 . Although, the mean values of MMP7 were higher than that of MMP11, this difference was not statistically significant $(P>.05)$.
We noticed that the difference in the mean levels of HBA were extremely significant compared to those of MMP7 \& MMP11 through day 1 to $5(P<.001)$ (Fig. 2).

\section{Discussion}

In the current study, GAPDH was used as a reference gene due to the fact that its transcription level remains relatively constant in response to experimental manipulation in most tissues ( $\mathrm{Li}$ et al., 2010). The same study instrument was adopted by other researches such as Bauer et al. (2008) and Hass et al. (2009), wherein GAPDH was detected in all body fluids including menstrual and peripheral blood.

Overall, HBA was detected in the entire study samples including menstrual and peripheral ones. This finding is consistent with previous studies where blood markers HBA and aminolevulinate synthase 2 (ALAS2) were expressed in both menstrual and peripheral blood (Nussbaumer et al., 2006; Hass et al., 2011; Jakubowska et al., 2014; Song et al., 2015).

This may be related to the fact that HBA and hemoglobin $B(\mathrm{HBB})$, as subunits of hemoglobin, are in the meantime ideal indicators for the presence of blood and menstrual secretion. The latter is comprised of a complex mixture of different tissue types including blood (30-50\%), degraded endometrial tissue and epithelial cells shed at the vaginal lumen (Lindenbergh et al., 2012; Zhao et al., 2017).

Our results supported the fact that the matrix metalloproteinases (MMP7 and MMP11) are involved in the cleavage of extracellular matrix proteins and in tissue remodeling. Thus, in the endometrium, they function to break down the extracellular matrix of the endometrial stroma (Farage \& Maibach, 2016; Jakubowska et al., 2014).

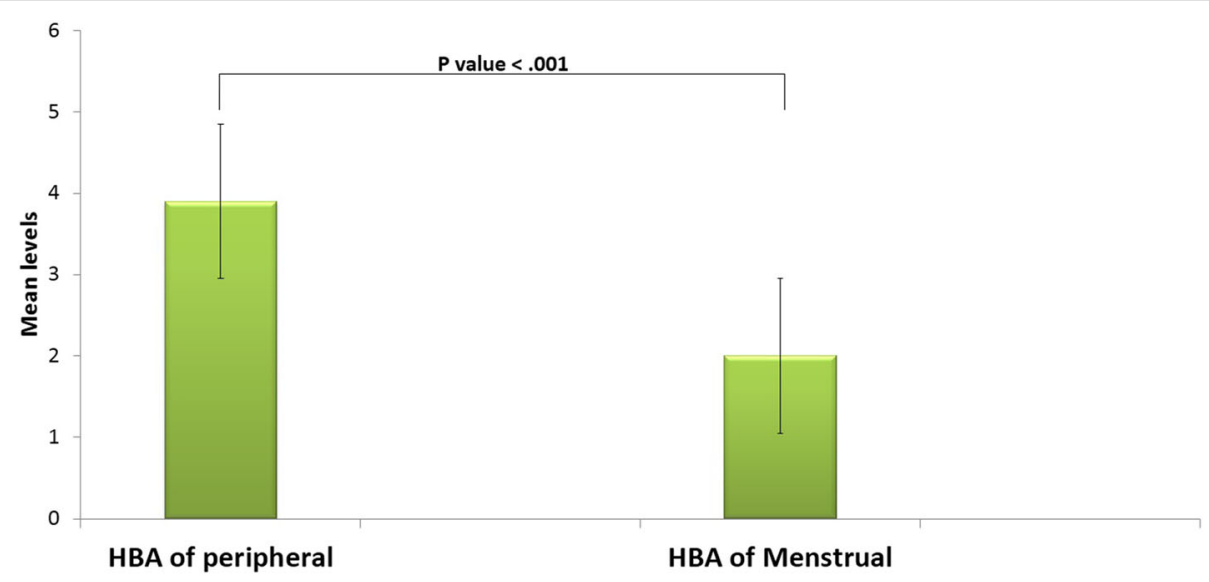

Fig. $1 \mathrm{HBA}$ in peripheral (male and female participants) and menstrual blood samples 
Table 3 Comparison between MMP7\&MMP11 mean through different days of menses

\begin{tabular}{lllllll}
\hline & Day 1 & Day 2 & Day 3 & Day 4 & Day 5 & $P$ value \\
\hline MMP7 & $1.15 \pm 0.72$ & $1.03 \pm 0.63$ & $1.18 \pm 0.82$ & $0.93 \pm 0.38$ & $0.72 \pm 0.37$ & 0.67 \\
MMP11 & $0.78 \pm 0.32$ & $0.94 \pm 0.32$ & $0.93 \pm 0.60$ & $0.70 \pm 0.19$ & $0.55 \pm 0.29$ & 0.25 \\
\hline
\end{tabular}

Similar to other studies, MPP7\&11 were detected in all menstrual blood samples with absolute absence from peripheral blood samples. However, this finding was in contrast to the study conducted by Roeder et al. (2013), who showed poor specificity of MMP7 and MMP11 for differentiating menstrual from blood samples. This difference can be attributed to the difference in RNA amount added to their reactions; nonspecific signals might have occurred as a result of too much RNA with subsequent fallacies. Such findings raise concerns about the importance of standardization of RNA amount involved in the corresponding reactions (Jakubowska et al.,2014).

In the current work, the difference in the mean levels of HBA in both peripheral and menstrual blood samples was extremely significant with higher mean value among peripheral blood samples. This could be related to insufficient quantity and quality of blood obtained from menstrual samples by that menstrual blood samples lacked blood in both quantity. Only $30 \%$ to $50 \%$ of samples are blood with high percentage of mRNA degradation, therefore, it is not to be expected that menstrual blood will show the same expression levels as peripheral one (Hass et al., 2009; song et al.,2015). In the same context, comparison between HBA mean values exhibited a significant descending pattern through 1 st 5 days of menses $(P=.0159)$. Variation in gene expression expected over the reported days of menstruation, especially towards the end of menstruation, as menstrual blood flow can vary significantly may be the factor that influenced such pattern (Hass et al., 2014).

In terms of metalloproteinases, the mean levels of MMP11 in menstrual blood had rising pattern reaching its peak on the 2nd day (0.94) and 3rd day (0.93) of menses then declined to its lowest values on 4th and 5th days, however this difference was not statistically significant. Although these results were consistent with previous work of Bauer and Patzelt, (2008) who reported reduced expression of MMP11 on day one (62\%) compared to on days 2 and 3 (90-94\%), however Hass and his colleagues

Table 4 Mean levels of HBA through different days of menses

\begin{tabular}{lllllll}
\hline & Day 1 & Day 2 & Day 3 & Day 4 & Day 5 & $P$ value \\
\hline HBA & 3.6 & 3.8 & 3.02 & 2.43 & 1.67 & $0.01^{*}$ \\
& \pm 1.32 & \pm 0.63 & \pm 1.91 & \pm 1.89 & \pm 2.13 & \\
\hline
\end{tabular}

"significant $P<0.05$
(2014) could not confirm that, which might be due to the time point of sample taking and inter-individual differences.

In the same setting, expression of MMP7 was declined throughout the days of menses with the highest mean value was in the third day and the lowest mean value was in the fifth day, with no significant difference. It was in accordance with other studies which evaluated the variation in marker detection amongst the samples from day one to day four of menstruation and concluded that the expression of menstrual blood markers varies depending on the day that sampling has occurred (Hass et al., 2014; Patel and Peel 2008).

Based on their mean values, MMP7 and MMP 11 showed no significant difference throughout days of menses from day one to day five. This is consistent with other studies where MMP7 and MMP11 appeared equally useful in the determination of menstrual secretion although MMP7 seems to be more sensitive; as higher signals were obtained when compared to MMP11 throughout menstrual days (Hass et al., 2009; Song et al., 2015; Lindenbergh et al., 2012; Xu et al., 2014).

A former study conducted by Bauer and Patzelt (2008) employing Real Time PCR revealed that MMP7 expression is a strong evidence for the menstrual sample. Their findings were inconsistent with the results generated in our study wherein MMP11 expression was found to be more constant and stronger than MMP7 expression during menstruation. Similarly, Hass and his colleagues found the MMP7 marker to be more suitable than the MMP11 marker in delimiting the menstrual period (days 1-4), since some vaginal secretion samples (days 6-28) revealed high MMP11 expression (Hass et al., 2009).

This highlights the truth that if a forensic sample is recovered from the first day of menses where endometrial cells are completely or partially absent and mRNA from

Table 5 Distribution of the mean values of MMP7 and MMP11 through different days of menstruation

\begin{tabular}{llll}
\hline & MMP7 & MMP11 & $P$ value \\
\hline Day one & $1.15 \pm 0.72$ & $0.78 \pm 0.32$ & 0.14 \\
Day two & $1.04 \pm 0.63$ & $0.94 \pm 0.31$ & 0.65 \\
Day three & $1.19 \pm 0.82$ & $0.93 \pm 0.60$ & 0.45 \\
Day four & $0.93 \pm 0.37$ & $0.70 \pm 0.19$ & 0.16 \\
Day five & $0.72 \pm 0.37$ & $0.55 \pm 0.29$ & 0.44 \\
\hline
\end{tabular}




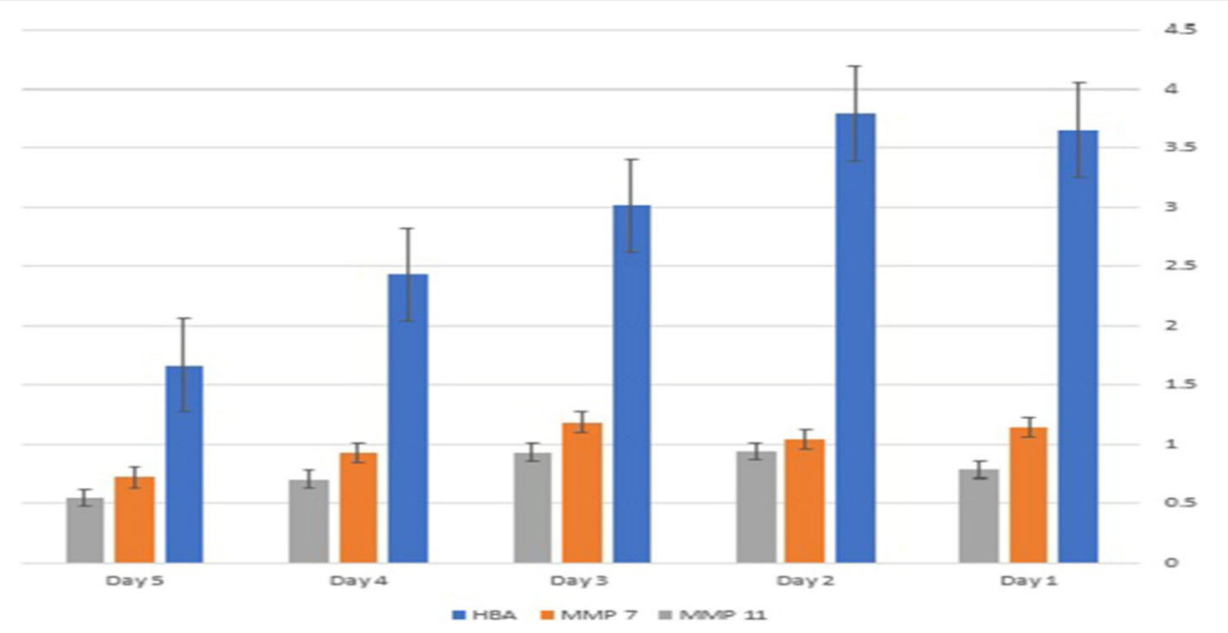

Fig. 2 Mean levels of HBA, MMP7 and MMP11 through different days of menstruation with higher levels of HBA, MMP7 than MMP11 throughout the days

the MMP11 gene are still in low levels which cannot be utilized for forensic analysis (Bauer \& Patzelt 2002). MMP7 is thought to be more relevant as a marker for mRNA amplification because it can be amplified by the use of easily acquired commercially produced testing kits for immediate use in a forensic laboratory. MMP7 has smaller amplicon size (101 base pairs bp) in comparison to MMP11 (455 bp) that makes MMP11 a less valuable marker for menstrual blood identification in a forensic laboratory (Counsil and McKillip, 2010). Moreover, despite the successful reduction of MMP11 amplicon size down to $200 \mathrm{bp}$ in some studies it is still much larger than mRNA amplified from the MMP7 menstrual blood marker (Ferri et al., 2004).

\section{Conclusion}

HBA, MMP7\&MMP11 could be useful markers for differentiation between menstrual and peripheral blood stains using Real time RT-PCR which is a suitable technique to assess the mRNA expression. Further studies should be conducted on various fabrics as jeans, wood, towels and glass containing peripheral and menstrual stains, also studies including detection of MMP7 \& MMP11 on other body fluids as urine, sweat, vaginal fluid and semen to detect sensitivity and specifity of these markers as forensic markers for detection of menstrual blood.

\section{Abbreviations}

ALAS2: Aminolevulinate synthase 2; ANOVA: One-way analysis of variance; bp: Base pairs; C: Celsius; Ct: Cycle threshold; DNasel: Deoxyribonuclease inhibitor; F: Fahrenheit; GAPDH: Glyceraldehyde 3-phosphate dehydrogenase; H: Hour; HBA: Hemoglobin alpha; LDH: Lactate dehydrogenase; Min: Minute; MMP: Matrix metalloproteinases; mRNA: Messenger ribonucleic acid; p: Probability; qRT-PCR: Real time reverse transcription-polymerase chain reaction; RNA: Ribonucleic acid; RQ: Relative Quantification; SD: Standard deviation; Sec: Second; SPSS: Statistical package for the social sciences; Ml: Microliter
Funding

Cairo university.

Availability of data and materials

Data will not be shared with public access.

\section{Authors' contributions}

Dr. AM: the experimental work and writing the paper. Prof. HS: responsible of the experimental design of the research, starting from the idea, interpretation of results and critical revision of the paper. Dr. MH: assistance in writing and final revision. Prof. AA: final revision of the paper. Prof. DA: responsible for the practical part of the research. Dr. AA: assistance in writing and final revision. All authors read and approved the final manuscript.

Ethics approval and consent to participate

The study work was conducted after the approval of Ethical Committee, Faculty of medicine, Cairo University.

\section{Consent for publication}

Consent forms were given and signed by all subjects prior to participation.

\section{Competing interests}

The authors declare that they have no competing interests.

\section{Publisher's Note}

Springer Nature remains neutral with regard to jurisdictional claims in published maps and institutional affiliations.

\section{Author details}

'Department of Forensic Medicine and Clinical Toxicology, Faculty of Medicine, Cairo University, Cairo, Egypt. ${ }^{2}$ Department of Medical Biochemistry and Molecular Biology, Faculty of Medicine, Cairo University, Kasr Alainy Street, Cairo 11562, Egypt. ${ }^{3}$ Department of obstetrics and gynecology, Faculty of Medicine, Cairo University, Kasr Alainy Street, Cairo 11562, Egypt.

Received: 6 March 2018 Accepted: 14 June 2018

Published online: 21 June 2018

\section{References}

Bauer M, Patzelt D (2002) Evaluation of mRNA markers for the identification of menstrual blood. Journal of Forensic Science 47(6):1278-1282

Bauer M, Patzelt D (2008) Identification of menstrual blood by real time RT-PCR: technical improvements and the practical value of negative test results. Forensic Sci Int 174(1):55-59 
Counsil TI, McKillip JL (2010) Forensic blood evidence analysis using RNA targets and novel molecular tools. Biologia 65(2):175-182

Farage MA, Maibach HI (eds) (2016) The vulva: anatomy, physiology, and pathology. CRC Press

Ferri G, Bini C, Ceccardi S, Pelotti S (2004) Successful identification of two years old menstrual bloodstain by using MMP-11 shorter amplicons. J Forensic Sci 49(6):1387

Haas C, Hanson E, Anjos MJ, Ballantyne KN, Banemann R, Bhoelai B, Borges E, Carvalho M, Courts C, De Cock G, Drobnic K (2014) RNA/DNA co-analysis from human menstrual blood and vaginal secretion stains: results of a fourth and fifth collaborative EDNAP exercise. Forensic Science International: Genetics. 8(1):203-212

Haas C, Hanson E, Kratzer A, Bär W, Ballantyne J (2011) Selection of highly specific and sensitive mRNA biomarkers for the identification of blood. Forensic Science International: Genetics 5(5):449-458

Haas C, Klesser B, Maake C, Bär W, Kratzer A (2009) mRNA profiling for body fluid identification by reverse transcription endpoint PCR and realtime PCR. Forensic Science International: Genetics. 3(2):80-88

Jakubowska J, Maciejewska A, Bielawski KP, Pawłowski R (2014) mRNA heptaplex protocol for distinguishing between menstrual and peripheral blood. Forensic Science International: Genetics. 13:53-60

Li Z, Yang L, Wang J, Shi W, Pawar RA, Liu Y, Xu C, Cong W, Hu Q, Lu T, Xia F (2010) $\beta$-Actin is a useful internal control for tissue-specific gene expression studies using quantitative real-time PCR in the half-smooth tongue sole Cynoglossus semilaevis challenged with LPS or Vibrio anguillarum. Fish \& shellfish immunology 29(1):89-93

Lindenbergh A, de Pagter M, Ramdayal G, Visser M, Zubakov D, Kayser M, Sijen T (2012) A multiplex (m) RNA-profiling system for the forensic identification of body fluids and contact traces. Forensic Science International: Genetics. 6(5):565-577

Nussbaumer C, Gharehbaghi-Schnell E, Korschineck I (2006) Messenger RNA profiling: a novel method for body fluid identification by real-time PCR. Forensic Sci Int 157(2-3):181-186

Patel G, Peel C (2008) Identifying the origin of cells. Forensic Science International: Genetics Supplement Series 1(1):574-576

Roeder AD, Haas C (2013) mRNA profiling using a minimum of five mRNA markers per body fluid and a novel scoring method for body fluid identification. Int J Legal Med 127(4):707-721

Song F, Luo H, Hou Y (2015) Developed and evaluated a multiplex mRNA profiling system for body fluid identification in Chinese Han population. J Forensic Legal Med 35:73-80

Takamura A, Watanabe K, Akutsu T (2017) Advanced forensic validation for human spermatozoa identification using SPERM HY-LITER ${ }^{\text {TM }}$ express with quantitative image analysis. Int J Legal Med 131(4):933-939

Virkler K, Lednev IK (2009) Analysis of body fluids for forensic purposes: from laboratory testing to non-destructive rapid confirmatory identification at a crime scene. Forensic Sci Int 188(1-3):1-7

World Medical Association (2001) World medical association declaration of Helsinki. Ethical principles for medical research involving human subjects. Bull World Health Organ 79(4):373

Xu Y, Xie J, Cao Y, Zhou H, Ping Y, Chen L, Gu L, Hu W, Bi G, Ge J, Chen X (2014) Development of highly sensitive and specific mRNA multiplex system (XCYR1) for forensic human body fluids and tissues identification. PLoS One 9(7):e100123

Zhao H, Wang C, Yao L, Lin Q, Xu X, Hu L, Li W (2017) Identification of aged bloodstains through mRNA profiling: experiments results on selected markers of 30-and 50-year-old samples. Forensic Sci Int 272:e1-e6

\section{Submit your manuscript to a SpringerOpen ${ }^{\mathcal{O}}$ journal and benefit from:}

- Convenient online submission

- Rigorous peer review

- Open access: articles freely available online

- High visibility within the field

- Retaining the copyright to your article 